\title{
Ticagrelor versus clopidogrel in patients with acute coronary syndromes intended for non-invasive management: substudy from prospective randomised PLATelet inhibition and patient Outcomes (PLATO) trial
}

\author{
Stefan $\mathrm{K}$ James associate professor ${ }^{1}$, Matthew T Roe associate professor ${ }^{2}$, Christopher P Cannon \\ associate professor ${ }^{3}$, Jan $\mathrm{H}$ Cornel cardiologist ${ }^{4}$, Jay Horrow executive director, global medicines \\ development ${ }^{5}$, Steen Husted chief of thrombosis unit ${ }^{6}$, Hugo Katus chief of the department of internal \\ medicine, head of cardiology ${ }^{7}$, Joao Morais chief of cardiology ${ }^{8}, \mathrm{Ph}$ Gabriel Steg professor ${ }^{910}{ }^{11}$, \\ Robert F Storey professor ${ }^{12}$, Susanna Stevens senior biostatistician ${ }^{2}$, Lars Wallentin professor ${ }^{1}$, \\ Robert A Harrington professor ${ }^{2}$
}

\footnotetext{
${ }^{1}$ Uppsala Clinical Research Center, Uppsala University, Uppsala, Sweden; ${ }^{2}$ Duke Clinical Research Institute, Durham, NC, USA; ${ }^{3}$ TIMI Study Group, Brigham and Women's Hospital, Boston, MA, USA; ${ }^{4}$ Medisch Centrum Alkmaar, Alkmaar, Netherlands; ${ }^{5}$ AstraZeneca R\&D, Wilmington, DE, USA; ${ }^{6}$ Department of Cardiology, Århus University Hospital, Århus, Denmark; ${ }^{7}$ Medizinische Klinik, Universitätsklinikum Heidelberg, Germany; ${ }^{8}$ Santo Andre's Hospital, Leiria, Portugal; IINSERM U-698, Paris, France; ${ }^{10}$ Université Paris 7, Paris, France; ${ }^{11}$ Hôpital Bichat, AP-HP, Paris, France; ${ }^{12}$ Department of Cardiovascular Science, University of Sheffield, Sheffield, UK
}

\begin{abstract}
Objective To evaluate efficacy and safety outcomes in patients in the PLATelet inhibition and patient Outcomes (PLATO) trial who at randomisation were planned for a non-invasive treatment strategy.

Design Pre-specified analysis of pre-randomisation defined subgroup of prospective randomised clinical trial.

Setting 862 centres in 43 countries.

Participants 5216 (28\%) of 18624 patients admitted to hospital for acute coronary syndrome who were specified as planned for non-invasive management.

Interventions Randomised treatment with ticagrelor $(n=2601)$ versus clopidogrel (2615).

Main outcome measurements Primary composite end point of cardiovascular death, myocardial infarction, and stroke; their individual components; and PLATO defined major bleeding during one year.

Results 2183 (41.9\%) patients had coronary angiography during their initial hospital admission, 1065 (20.4\%) had percutaneous coronary intervention, and 208 (4.0\%) had coronary artery bypass surgery. Cumulatively, 3143 (60.3\%) patients had been managed non-invasively by the end of follow-up. The incidence of the primary end point was lower with ticagrelor than with clopidogrel $(12.0 \%(\mathrm{n}=295) v 14.3 \%(346)$; hazard ratio $0.85,95 \%$ confidence interval 0.73 to $1.00 ; \mathrm{P}=0.04)$. Overall
\end{abstract}

mortality was also lower $(6.1 \%(147) v 8.2 \%(195) ; 0.75,0.61$ to 0.93 ; $\mathrm{P}=0.01)$. The incidence of total major bleeding $(11.9 \%(272) v 10.3 \%$ (238); $1.17,0.98$ to $1.39 ; \mathrm{P}=0.08)$ and non-coronary artery bypass grafting related major bleeding $(4.0 \%(90) v 3.1 \%(71) ; 1.30,0.95$ to $1.77 ; \mathrm{P}=0.10$ ) was numerically higher with ticagrelor than with clopidogrel.

Conclusions In patients with acute coronary syndrome initially intended for non-invasive management, the benefits of ticagrelor over clopidogrel were consistent with those from the overall PLATO results, indicating the broad benefits of P2Y12 inhibition with ticagrelor regardless of intended management strategy.

Trial registration Clinical trials NCT00391872.

\section{Introduction}

In patients with non-ST elevation acute coronary syndrome with moderate to high risk characteristics, current guidelines recommend an invasive strategy with angiography followed by percutaneous coronary intervention or coronary artery bypass grafting if appropriate. ${ }^{12}$ However, the Invasive versus Conservative Treatment in Unstable Coronary Syndromes (ICTUS) trial supports a conservative, non-invasive strategy with intensive medical treatment and invasive procedures only in case of signs or symptoms of ischaemia, ${ }^{3}$ and this is 
considered an appropriate treatment strategy for non-ST elevation acute coronary syndrome in patients at lower risk. ${ }^{1} \mathrm{~A}$ considerable proportion of patients do not have angiography or revascularisation during the initial hospital admission. ${ }^{45}$ However, dual antiplatelet treatment with aspirin and the P2Y12 inhibitor clopidogrel is recommended for 12 months in all patients with non-ST elevation acute coronary syndrome, as both patients who had revascularisation and those managed medically derived benefit in post hoc analyses from the Clopidogrel in Unstable angina to prevent Recurrent Events (CURE) trial. ${ }^{67}$ No clinical trial has prospectively evaluated $\mathrm{P} 2 \mathrm{Y} 12$ inhibitors in patients intended for an initial non-invasive management strategy.

The PLATelet inhibition and patient Outcomes (PLATO) trial found that the reversibly binding oral P2Y12-inhibitor ticagrelor was superior to clopidogrel for the prevention of the composite end point of death from vascular causes, myocardial infarction, and stroke, as well as vascular death in itself and total death, without an increase in major bleeding, in a broad population of patients with acute coronary syndromes starting treatment as soon as possible after hospital admission. ${ }^{8}$ A pre-specified objective of the PLATO trial was to compare ticagrelor and clopidogrel in the stratum of patients with non-ST elevation acute coronary syndrome whom, at randomisation, the treating physician stated as planned for a non-invasive treatment strategy. ${ }^{9}$ Selection of a strategy before randomisation provides the opportunity to do a proper statistical comparison between the groups. ${ }^{10}$

\section{Methods}

\section{Design overview}

The PLATO trial enrolled 18624 patients from 43 countries between October 2006 and July 2008. Details of the design, patients, outcome definitions, and results have been published. ${ }^{89}$ Patients were included if they were admitted to hospital with ST segment elevation acute coronary syndrome scheduled for primary percutaneous coronary intervention or non-ST segment elevation acute coronary syndrome, with onset of symptoms during the previous 24 hours. For non-ST segment elevation acute coronary syndrome, at least two of the following three criteria were required: ST segment depression or transient elevation of at least $1 \mathrm{~mm}$ in two or more contiguous leads; a positive biomarker indicating myocardial necrosis; and one additional risk indicator, including age over 60 years, previous myocardial infarction or coronary artery bypass grafting, carotid artery disease, previous ischaemic stroke, transient ischaemic attack, carotid stenosis, cerebral revascularisation, diabetes mellitus, peripheral artery disease, or chronic renal dysfunction (creatinine clearance $<60 \mathrm{~mL} / \mathrm{min}$ ). The most important exclusion criteria included contraindication to clopidogrel, fibrinolytic treatment within 24 hours, need for oral anticoagulation treatment, need for dialysis, and clinically important anaemia or thrombocytopenia.

\section{Setting and participants}

At the time of randomisation, the treating physician designated patients as planned for initial invasive management or initial conservative management in the interactive voice randomisation system. The investigator answered the following question just before randomisation: "Concerning this patient, do you intend to use an invasive strategy, with coronary angiography followed by revascularisation based on the coronary anatomy, or a non-invasive strategy?" These designations were considered to be non-binding but created statistically proper pre hoc subgroups for this analysis. After randomisation, subsequent decisions to do angiography and revascularisation based on changes in the patients' clinical statuses were not restricted.

\section{Randomisation and interventions}

Patients were randomly assigned to ticagrelor or clopidogrel. Ticagrelor was given in a loading dose of $180 \mathrm{mg}$ followed by $90 \mathrm{mg}$ twice daily. Patients randomised to clopidogrel who had not received an open label loading dose and had not been taking clopidogrel for at least five days before randomisation received a $300 \mathrm{mg}$ loading dose of clopidogrel study drug followed by $75 \mathrm{mg}$ daily. Others continued a maintenance dose of $75 \mathrm{mg}$ clopidogrel daily. All patients received acetylsalicylic acid (aspirin) unless they were intolerant of it. The randomised treatment continued for a minimum of six months and a maximum of 12 months; the median length of study treatment in the overall population was 9.1 months.

\section{Outcomes and follow-up}

The primary efficacy end point was the composite of death from vascular causes, myocardial infarction, or stroke. ${ }^{8} 9$ Secondary end points included the individual components of the primary end point; all cause mortality; non-vascular mortality; death from vascular causes or myocardial infarction, stroke, severe recurrent cardiac ischaemia, recurrent cardiac ischaemia, transient ischaemic attack, or other arterial thrombotic event; stroke subclassified as ischaemic, haemorrhagic, and unknown. Death from vascular causes included cardiovascular deaths, cerebrovascular deaths, or any other death for which no non-vascular cause was clearly documented.

The primary safety end point was PLATO defined total major bleeding. Definitions of bleeding used in the trial have been previously published. ${ }^{9}$ An independent central adjudication committee, unaware of the group assignments, adjudicated all primary and secondary end points and major and minor bleeding events. TIMI major bleeding was programmed from the electronic case report form, using a cut-off point of $\geq 5 \mathrm{~g} / \mathrm{dL}$ haemoglobin, but did not necessarily require clinical evidence of excessive bleeding after coronary artery bypass grafting.

\section{Statistical analysis}

The analysis was a pre-specified stratum of the total trial. We used univariable Cox proportional hazards models to analyse the primary and secondary end point results. We present Kaplan-Meier curves for each treatment group for selected end points and procedures. We present estimates of the end points for each treatment group as the Kaplan-Meier rates at 360 days and total number of events during follow-up. When we analysed subgroups, we derived the $\mathrm{P}$ value for interaction from a Cox model containing subgroup membership, treatment, and the subgroup by treatment interaction. We used the intention to treat principle and SAS version 9.2 for all analyses. We used a $P$ value of 0.05 as a critical value determining statistical significance of the overall treatment differences.

\section{Results \\ Patients}

The PLATO trial recruited 18624 patients with acute coronary syndrome (with or without ST elevation) from 862 centres in 43 countries between October 2006 and July 2008. At the time of randomisation, $5216(28 \%)$ patients were specified by the investigator as being intended for a non-invasive treatment strategy (fig 1). Of these, 2601 patients were randomised to 
ticagrelor and 2615 to clopidogrel. The median age was 65 years, and $36.5 \%$ were women (table 1). The median time from onset of symptoms to randomisation was 16.6 (interquartile range 9.1-22.0) hours, and the duration of the randomised treatment was 276 (175-365) days. Despite the initial intent for a non-invasive approach, 2183 (41.9\%) patients had coronary angiography during the initial hospital admission, at a median of 51 hours to in-hospital angiography; 1065 (20.4\%) had in-hospital percutaneous coronary intervention, at a median of 70 hours; and 208 (4.0\%) had in-hospital coronary artery bypass grafting at a median of 12 days (table 2). At the end of follow-up, $2040(40 \%)$ of the patients had had a revascularisation procedure; $1514(72.6 \%)$ of these had percutaneous coronary intervention only, 559 (25.8\%) had coronary artery bypass grafting only, and $33(1.6 \%)$ had both (fig 2). Most patients were diagnosed as having non-ST elevation myocardial infarction and unstable angina at discharge, but 451 patients (218 patients in the ticagrelor group and 233 in the clopidogrel group) had ST elevation myocardial infarction as their final diagnosis (table 2 and fig 1).

Compared with patients with intended invasive management, patients with intended non-invasive management were older, were more often women, and more often had cardiovascular risk factors such as diabetes, previous myocardial infarction, heart failure, stroke, and renal and peripheral artery disease (table 1). ${ }^{11}$ Furthermore, they had a higher average Thrombolysis In Myocardial Infarction (TIMI) non ST-elevation myocardial infarction risk score but less often had a positive troponin test (table 1). On the basis of the intended non-invasive management, unfractionated heparin, glycoprotein IIb/IIIa inhibitors, and bivalirudin were used less often but fondaparinux and low molecular weight heparin were used more often. During hospital admission, the proportion of patients who had coronary angiography was less than half, percutaneous coronary intervention about a quarter, and coronary artery bypass grafting slightly more than two thirds those of the invasive cohort (table 2).

\section{Outcomes}

The incidence of the primary composite end point was significantly lower with ticagrelor than with clopidogrel (14.3\% $v 12.0 \%$; hazard ratio $0.85,95 \%$ confidence interval 0.73 to $1.00 ; \mathrm{P}=0.04)$. All cause mortality was reduced from $8.2 \%$ to $6.1 \%$ (hazard ratio $0.75,0.61$ to $0.93 ; \mathrm{P}=0.01$ ) and cardiovascular mortality from $7.2 \%$ to $5.5 \%$ (0.76, 0.61 to 0.96 ; $\mathrm{P}=0.02$ ) with use of ticagrelor rather than clopidogrel. The rate of myocardial infarction and the composite of cardiovascular death and other thromboembolic events did not differ significantly between the groups. Rates of stroke were not significantly different, although numerically more haemorrhagic strokes occurred in the ticagrelor group (table 3 ).

Compared with patients with intended invasive treatment, patients with intended non-invasive management had an initially lower primary event rate, but the event curves crossed at approximately 30 days and increased more over time (fig 3 ). The benefit for ticagrelor compared with clopidogrel was consistent between the two cohorts; the hazard ratio was 0.85 ( 0.85 to 1.00$)$ in the non-invasive cohort and 0.84 (0.75 to 0.94$)$ in the invasive cohort ( $\mathrm{P}$ for interaction $=0.89$ ). The total mortality was higher in the intended non-invasive cohort than in the intended invasive cohort during the entire course of the study (fig 4), but the relative benefit with ticagrelor was consistent (hazard ratio 0.75 ( 0.61 to 0.93 ) v 0.80 (0.61 to 0.93 ): $\mathrm{P}$ for interaction $=0.64)$.

\section{Bleeding}

We found no statistically significant difference in the rates of PLATO defined total major bleeding: $11.9 \%$ for ticagrelor treated patients and $10.3 \%$ for clopidogrel treated patients (hazard ratio $1.17,0.98$ to $1.39 ; \mathrm{P}=0.08$ ) (fig 5, table 3 ). Nor did we find any significant difference between the randomised groups when we used the TIMI definition of major bleeding. The incidence of life threatening or fatal major bleedings did not differ between the groups. Numerically more intracranial bleedings occurred in the ticagrelor group, but the difference was not statistically significant. We found a significantly higher incidence of PLATO defined other major bleedings and of the composite of major and minor bleedings in the ticagrelor group owing to a higher incidence of bleedings related to non-coronary artery bypass grafting during long term treatment.

\section{Outcome in subgroups}

In the overall PLATO population, 7955 patients had non-ST elevation acute coronary artery syndrome as their final diagnosis. Among these, 2910 (36.6\%) patients were intended for non-invasive management at the time of randomisation. The result for ticagrelor compared with clopidogrel in this subgroup was consistent with the overall results in the non-invasive cohort, with non-significant diagnosis by treatment interactions for the primary outcome $(\mathrm{P}=0.58)$, mortality $(\mathrm{P}=0.91)$, and major bleeding $(\mathrm{P}=0.90)$. Among the intended non-invasively managed patients, 87 patients in the ticagrelor group were admitted without persistent ST elevation or new left bundle branch block but had ST elevation myocardial infarction as their final diagnosis compared with 103 patients in the clopidogrel group. Also, among 3948 patients who did not actually have revascularisation during their hospital admission despite the initially intended management strategy (as a post-randomisation decision), ticagrelor reduced the primary outcome compared with clopidogrel, consistent with the overall results, from $15.2 \%$ (726) to $12.2 \%$ (224) (hazard ratio $0.81,0.68$ to 0.97 ).

\section{Significant versus insignificant coronary disease among patients who had in-hospital angiography}

Of all patients (intended invasive and non-invasive) who had coronary angiography during hospital admission, significant coronary disease, defined as at least one stenosis greater than $50 \%$, was found in $10755 / 11503(94 \%)$ of those who were intended for invasive management and in 596/674 (89\%) of those who were initially intended for non-invasive management. Patients with no significant disease had numerically lower event rates compared with those who were discovered to have significant disease. The primary composite event rate and mortality were consistently numerically lower in the ticagrelor group compared with the clopidogrel group, with no increase in major bleeding, independent of angiographic findings.

\section{Discussion}

This substudy of the PLATO trial indicates that treatment with ticagrelor compared with clopidogrel reduces major ischaemic events without significantly increasing major bleeding across the spectrum of management strategies for acute coronary syndrome. The unique design of the trial, with collection of information about the intended management strategy at the time of randomisation, allowed us to investigate the outcome of the randomised treatments in patients with an intended non-invasive treatment strategy without interference from post-randomisation treatment selections. This patient population has been 
under-represented in most clinical trials, and no other oral platelet inhibitor has been prospectively investigated in the setting of a primary non-invasive management strategy.

\section{Comparison with other studies}

The Global Utilisation of Strategies To prevent Occluded arteries IV (GUSTO IV) trial prospectively showed a high level of platelet inhibition achieved with the glycoprotein IIb/IIIa receptor inhibitor abciximab during 24 or 48 hours compared with placebo in patients with non-ST elevation acute coronary syndrome who were intended for initial medical management. ${ }^{12}$ However, in contrast to the significant benefit of abciximab that has been shown in patients with acute coronary syndrome having percutaneous coronary intervention, abciximab increased the incidence of bleeding and did not reduce ischaemic end points in this trial that encouraged an early non-invasive management strategy.$^{13}$ Clopidogrel versus placebo in addition to aspirin for acute coronary syndrome has not been evaluated prospectively in patients not intended for invasive management. However, the Clopidogrel in Unstable angina to prevent Recurrent ischemic Events (CURE) trial showed consistent benefit whether or not revascularisation was actually done. ${ }^{14}$ The ongoing TRILOGY (NCT00699998) trial is investigating the efficacy and safety of the thienopyridine prasugrel compared with clopidogrel in patients at high risk selected for medical management of acute coronary syndrome.

In the PLATO trial, $28 \%$ of the total patient population and $37 \%$ of the patients with a final diagnosis of non-ST elevation acute coronary artery syndrome were designated as planned for initial non-invasive management by the treating physician. Several registries and clinical trials have shown that $30-60 \%$ of patients admitted with non-ST elevation acute coronary syndrome in the Western world do not actually have cardiac catheterisation during hospital admission and $45-80 \%$ of patients do not have revascularisation. ${ }^{4515} 16$ The patients in PLATO intended for non-invasive management had a higher long term event rate than did those intended for invasive management, ${ }^{11}$ probably related in part to their high risk profile at baseline. These findings are consistent with registry data and post hoc analyses from clinical trials showing an up to twofold higher event rate compared with patients who have revascularisation. ${ }^{17}$ The shape of the event curves for the primary outcome differed between the invasive and non-invasive cohorts, with a higher early event rate in the invasive cohort and crossing event curves reflecting the different distributions of ST elevation and non-ST elevation acute coronary syndrome in the two cohorts and peri-procedural events.

\section{Invasive management}

Despite an intended non-invasive strategy at the time of randomisation, approximately half of the patients had coronary angiography, a third had percutaneous coronary intervention, and one tenth had coronary artery bypass grafting during the course of the study for emerging clinical indications. The relative reduction of the primary ischaemic end point and mortality by ticagrelor compared with clopidogrel was independent of the initial pre-randomisation treatment strategy, without any significant increase in major bleeding. Although the results in subgroups based on post-randomisation clinical data and treatment options have to be interpreted with caution, the benefit of ticagrelor compared with clopidogrel was consistent with the overall trial results. Thus, the results were in favour of ticagrelor whether or not revascularisation was actually done post-randomisation and whether or not significant coronary disease was found at any angiography during hospital admission.

\section{Safety}

Although rates of PLATO defined overall major bleeding did not differ significantly between the randomised groups, an excess of minor bleedings occurred, particularly of those not related to coronary artery bypass grafting during long term treatment. We also found a numerical increase in intracerebral bleedings, although the numbers were very small. The higher incidence of minor bleedings should be taken into consideration in patients at low risk not intended for invasive treatment, as patients at low risk of thromboembolic events have a low potential benefit from more extensive antithrombotic treatment and bleeding complications tend to accrue over time.

\section{Conclusion and implications}

In a population of patients with acute coronary syndrome managed with a planned non-invasive treatment strategy, more intense P2Y12 receptor inhibition with ticagrelor achieved a clinically important reduction in ischaemic events and mortality, but without increasing major bleeding, compared with clopidogrel. These results indicate the broad benefits of intensified P2Y12 inhibition for patients with acute coronary syndrome across management strategies.

Contributors: SKJ participated in study design; data gathering, analysis, and interpretation; writing the first draft; and all revisions of the report. CPC, JH, SH, HK, PGS, RFS, LW, and RAH were involved in study design; data gathering, analysis, and interpretation; and revision of the report. MTR, JK, and JM participated in data gathering and interpretation and revision of the report. SS was involved in data analysis and revision of the report. All authors had full access to all of the data (including statistical reports and tables) in the study and can take responsibility for the integrity of the data and the accuracy of the data analysis. SKJ is the guarantor.

Funding: This work was supported by AstraZeneca, who funded the PLATO trial. Representatives of the sponsor were involved in study design; data gathering, analysis, and interpretation; and revision of the report. Support for the analysis and interpretation of results and preparation of the manuscript was provided through funds to the Uppsala Clinical Research Center and Duke Clinical Research Institute as part of the clinical study agreement.

Competing interests: All authors have completed the Unified Competing Interest form at www.icmje.org/coi_disclosure.pdf (available upon request from the corresponding author). SKJ declares research grants and advisory board fees from AstraZeneca and honorariums from AstraZeneca, Bristol-Myers Squibb, Schering-Plough, Merck, and Eli-Lilly. MTR declares research grants from Eli Lilly, Bristol-Myers Squibb, Sanofi-Aventis, and Merck/Schering-Plough; consulting fees or honorariums from GlaxoSmithKline, Novartis, Eli Lilly, Bristol-Myers Squibb, Sanofi-Aventis, Merck/Schering-Plough, and AstraZeneca. CPC receives research grants/support from Accumetrics, AstraZeneca, Glaxo-SmithKline, Intekrin Therapeutics, Merck, and Takeda; has served on advisory boards for Bristol-Myers Squibb/Sanofi-Aventis, Novartis, and Alnyam (but donates funds to charity); receives honorariums for development of independent educational symposiums from Pfizer and AstraZeneca; and is a clinical adviser for and holds equity in Automedics Medical Systems. JHC declares consulting fees from Eli Lilly and Pfizer. $\mathrm{JH}$ is an employee of AstraZeneca and has equity ownership in AstraZeneca. SH declares research grants from AstraZeneca, Bristol-Myers Squibb, Pfizer, and Bayer and consultant fees from Sanofi-Aventis, Pfizer, and AstraZeneca. HK declares consulting and lecture fees from AstraZeneca., Bayer, Daiichi, Sankoy, and Roche. JM declares research grants from AstraZeneca, Bayer, Daiichi Sankyo, MSD/Schering-Plough, and Eli Lilly. PGS declares research grants from Servier; consultant fees from/advisory board membership for Astellas, 


\section{What is already known on this topic}

Ticagrelor reduced ischaemic events and mortality compared with clopidogrel, with similar major bleeding rates, through 12 months in the PLATO trial

$30-60 \%$ of patients admitted with non-ST elevation acute coronary syndrome in the Western world do not have cardiac catheterisation during hospital admission, and $45-80 \%$ do not have revascularisation

No clinical trial has prospectively reported outcomes with P2Y12 inhibitors among patients intended for initial non-invasive management

\section{What this study adds}

In acute coronary syndrome patients initially intended for non-invasive management, ticagrelor achieved a clinically important reduction in ischaemic events and mortality compared with clopidogrel, without increasing major bleeding

The reduction of ischaemic events and mortality by ticagrelor over clopidogrel was consistent in acute coronary syndrome patients with non-ST elevation who did not actually have revascularisation

The benefits of intensified P2Y12 inhibition apply across different management strategies

AstraZeneca, Bayer, Boehringer Ingelheim, Bristol-Myers Squibb, Daiichi/Sankyo/Eli Lilly alliance, GlaxoSmithKline, Medtronic, Merck, Otsuka Pharmaceutical, Roche, Sanofi-Aventis, Servier, and the Medicines Company; and having equity ownership in Aterovax. RFS declares institutional grants from AstraZeneca, Dynabyte, Eli Lilly/Daiichi Sankyo alliance, Merck/Schering-Plough, and Accumetrics; honorariums from AstraZeneca, Eli Lilly/Daiichi Sankyo alliance, Novartis, Medscape, GlaxoSmithKline, and Merck/Schering-Plough; consultant fees from AstraZeneca, Eli Lilly/Daiichi Sankyo alliance, Merck/Schering-Plough, Novartis, Sanofi-Aventis/Bristol-Myers Squibb, the Medicines Company, and Accumetrics; travel support from AstraZeneca, Eli Lilly/Daiichi Sankyo alliance, and Merck/Schering-Plough. LW reports research grants from AstraZeneca, Boehringer Ingelheim, Bristol-Myers Squibb, GlaxoSmithKline, and Schering-Plough; honorariums from AstraZeneca, Boehringer Ingelheim, Bristol-Myers Squibb, GlaxoSmithKline, Schering-Plough, and Eli Lilly; consultant fees from Regado Biotechnologies, Athera Biotechnologies, Boehringer Ingelheim, AstraZeneca, GlaxoSmithKline, and Eli Lilly; and lecture fees from AstraZeneca, Boehringer Ingelheim, and Eli Lilly. RAH reports advisory board fees from Novartis, Portola Pharmaceutical, and Merck; consulting fees from AstraZeneca, Bristol-Myers Squibb, Merck, Novartis, Portola, and Sanofi-Aventis; honorariums/lecture fees from Eli Lilly, Merck, and AstraZeneca; grant support from AstraZeneca, Bristol-Myers Squibb, Portola Pharmaceutical, and Merck; travel support from AstraZeneca, Novartis, and Merck; and potential grant support from the Medicines Company.

Ethical approval: The trial was approved by ethical review boards. All patients gave a written informed consent.

Data sharing: The authors are willing to share the protocol and the statistical analysis plan for this study but will not be able to share the database.

1 Bassand JP, Hamm CW, Ardissino D, Boersma E, Budaj A, Fernandez-Aviles F, et al. Guidelines for the diagnosis and treatment of non-ST-segment elevation acute coronary syndromes. Eur Heart J 2007;28:1598-660.

2 Anderson JL, Adams CD, Antman EM, Bridges CR, Califf RM, Casey DE Jr, et al. ACC/AHA 2007 guidelines for the management of patients with unstable angina/non ST-elevation myocardial infarction: a report of the American College of Cardiology/American Heart Association Task Force on Practice Guidelines (Writing Committee to Revise the 2002 Guidelines for the Management of Patients With Unstable Angina/Non ST-Elevation Myocardial Infarction): developed in collaboration with the American College of Emergency Physicians, the Society for Cardiovascular Angiography and Interventions, and the Society of Thoracic Surgeons: endorsed by the American Association of Cardiovascular and Pulmonary Rehabilitation and the Society for Academic Emergency Medicine. Circulation 2007;116:e148-304.
3 De Winter RJ, Windhausen F, Cornel JH, Dunselman PH, Janus CL, Bendermacher PE, et al. Early invasive versus selectively invasive management for acute coronary syndromes. N Engl J Med 2005;353:1095-104.

4 Chan MY, Becker RC, Harrington RA, Peterson ED, Armstrong PW, White H, et al. Noninvasive, medical management for non-ST-elevation acute coronary syndromes. Am Heart J 2008;155:397-407.

5 Amsterdam EA, Peterson ED, Ou FS, Newby LK, Pollack CV Jr, Gibler WB, et al. Comparative trends in guidelines adherence among patients with non-ST-segment elevation acute coronary syndromes treated with invasive versus conservative management strategies: results from the CRUSADE quality improvement initiative. Am Heart $J$ 2009;158:748-54.

6 Budaj A, Yusuf S, Mehta SR, Fox KA, Tognoni G, Zhao F, et al. Benefit of clopidogrel in patients with acute coronary syndromes without ST-segment elevation in various risk groups. Circulation 2002;106:1622-6.

7 Yusuf S, Mehta SR, Zhao F, Gersh BJ, Commerford PJ, Blumenthal M, et al. Early and late effects of clopidogrel in patients with acute coronary syndromes. Circulation 2003;107:966-72.

8 Wallentin L, Becker RC, Budaj A, Cannon CP, Emanuelsson H, Held C, et al. Ticagrelor versus clopidogrel in patients with acute coronary syndromes. $\mathrm{N}$ Engl $\mathrm{J} \mathrm{Med}$ 2009;361:1045-57.

9 James S, Akerblom A, Cannon CP, Emanuelsson H, Husted S, Katus H, et al. Comparison of ticagrelor, the first reversible oral $\mathrm{P} 2 \mathrm{Y}(12)$ receptor antagonist, with clopidogrel in patients with acute coronary syndromes: rationale, design, and baseline characteristics of the PLATelet inhibition and patient Outcomes (PLATO) trial. Am Heart $J$ 2009;157:599-605.

10 Hirsch A, Windhausen F, Tijssen JG, Oude Ophuis AJ, van der Giessen WJ, van der Zee PM, et al. Diverging associations of an intended early invasive strategy compared with actual revascularization, and outcome in patients with non-ST-segment elevation acute coronary syndrome: the problem of treatment selection bias. Eur Heart J 2009;30:645-54.

11 Cannon CP, Harrington RA, James S, Ardissino D, Becker RC, Emanuelsson H, et al. Comparison of ticagrelor with clopidogrel in patients with a planned invasive strategy for acute coronary syndromes (PLATO): a randomised double-blind study. Lancet 2010;375:283-93.

12 Simoons ML. Effect of glycoprotein Illb/lla receptor blocker abciximab on outcome in patients with acute coronary syndromes without early coronary revascularisation: the GUSTO IV-ACS randomised trial. Lancet 2001;357:1915-24.

13 De Queiroz Fernandes Araujo JO, Veloso HH, Braga De Paiva JM, Filho MW, Vincenzo De Paola AA. Efficacy and safety of abciximab on acute myocardial infarction treated with percutaneous coronary interventions: a meta-analysis of randomized, controlled trials. Am Heart J 2004;148:937-43.

14 Mehta SR, Yusuf S, Peters RJ, Bertrand ME, Lewis BS, Natarajan MK, et al. Effects of pretreatment with clopidogrel and aspirin followed by long-term therapy in patients undergoing percutaneous coronary intervention: the PCI-CURE study. Lancet 2001;358:527-33.

15 Chan MY, Mahaffey KW, Sun LJ, Pieper KS, White HD, Aylward PE, et al. Prevalence, predictors, and impact of conservative medical management for patients with non-ST-segment elevation acute coronary syndromes who have angiographically documented significant coronary disease. JACC Cardiovasc Interv 2008;1:369-78.

16 Cohen MG, Filby SJ, Roe MT, Chen AY, Menon V, Stouffer GA, et al. The paradoxical use of cardiac catheterization in patients with non-ST-elevation acute coronary syndromes: lessons from the Can Rapid Stratification of Unstable Angina Patients Suppress Adverse Outcomes With Early Implementation of the ACC/AHA Guidelines (CRUSADE) quality improvement initiative. Am Heart J 2009;158:263-70.

17 Ottervanger JP, Armstrong P, Barnathan ES, Boersma E, Cooper JS, Ohman EM, et al. Association of revascularisation with low mortality in non-ST elevation acute coronary syndrome, a report from GUSTO IV-ACS. Eur Heart J 2004;25:1494-501.

Accepted: 21 April 2011

Cite this as: $B M J 2011 ; 342: d 3527$ 


\section{Tables}

\begin{tabular}{|c|c|c|c|c|}
\hline & \multicolumn{3}{|c|}{ Planned non-invasive } & \multirow[b]{2}{*}{ Planned invasive $(n=13408)$} \\
\hline & Ticagrelor $(n=2601)$ & Clopidogrel (n=2615) & Total $(n=5216)$ & \\
\hline \multicolumn{5}{|l|}{ Demographics } \\
\hline Median (IQR) age (years) & $66(57-73)$ & $65(57-73)$ & $65(57-73)$ & $61(53-69)(n=13406)$ \\
\hline Age $\geq 75$ years & $21.3(553)$ & $21.2(555)$ & $21.2(1108)$ & $13.2(1770)$ \\
\hline Women & 36.9 (961) & $36.1(945)$ & $36.5(1906)$ & $25.2(3382)$ \\
\hline Median (IQR) weight (kg) & $78(69-88)(n=2597)$ & $78(69-88)(n=2608)$ & $78(69-88)(n=5205)$ & $80(70-90)(n=13363)$ \\
\hline $\begin{array}{l}\text { Median (IQR) body mass index } \\
\left(\mathrm{kg} / \mathrm{m}^{2}\right)\end{array}$ & $27.3(24.6-30.4)(n=2592)$ & $27.4(24.6-30.4)(n=2603)$ & $27.3(24.6-30.4)(n=5195)$ & $27.4(24.8-30.4)(n=13337)$ \\
\hline \multicolumn{5}{|l|}{ Cardiovascular risk factors } \\
\hline Habitual smoker & $25.2(654 / 2600)$ & $25.8(675 / 2614)$ & $25.5(1329 / 5214)$ & $39.9(5349 / 13396)$ \\
\hline Hypertension & $71.8(1868 / 2600)$ & $72.4(1893)$ & $72.1(3761 / 5215)$ & $62.9(8422 / 13398)$ \\
\hline Dyslipidaemia & $47.0(1223 / 2600)$ & $45.5(1191)$ & $46.3(2414 / 5215)$ & $46.8(6275 / 13397)$ \\
\hline Diabetes mellitus & $30.6(796 / 2600)$ & $28.9(757)$ & $29.8(1553 / 5215)$ & $23.2(3109 / 13398)$ \\
\hline \multicolumn{5}{|l|}{ Medical history } \\
\hline Angina pectoris & $59.5(1547 / 2600)$ & $58.7(1536)$ & $59.1(3083 / 5215)$ & $39.4(5275 / 13398)$ \\
\hline Myocardial infarction & $28.9(752 / 2600)$ & $30.3(793)$ & $29.6(1545 / 5215)$ & $17.0(2279 / 13398)$ \\
\hline Congestive heart failure & $11.2(290 / 2600)$ & $12.4(324)$ & $11.8(614 / 5215)$ & $3.3(436 / 13$ 398) \\
\hline $\begin{array}{l}\text { Percutaneous coronary } \\
\text { intervention }\end{array}$ & $12.5(325 / 2600)$ & $12.8(335)$ & $12.7(660 / 5215)$ & $13.7(1832 / 13397)$ \\
\hline Coronary artery bypass graft & $6.7(175 / 2600)$ & 7.4 (194) & $7.1(369 / 5215)$ & $5.5(737 / 13398)$ \\
\hline Transient ischaemic attack & $3.9(101 / 2600)$ & $4.2(110)$ & $4.0(211 / 5215)$ & $2.1(288 / 13398)$ \\
\hline Non-haemorrhagic stroke & $5.5(144 / 2600)$ & $5.8(151 / 2614)$ & $5.7(295 / 5214)$ & $3.2(427 / 13398)$ \\
\hline Peripheral arterial disease & $7.3(191 / 2600)$ & $8.0(210)$ & $7.7(401 / 5215)$ & $5.5(743 / 13398)$ \\
\hline Chronic renal disease & $5.0(131 / 2600)$ & $5.5(143)$ & $5.3(274 / 5215)$ & $3.8(511 / 13398)$ \\
\hline \multicolumn{5}{|l|}{ Physical findings } \\
\hline Median (IQR) heart rate & $72(64-82)(n=2584)$ & $73(65-82)(n=2601)$ & $72(64-82)(n=5185)$ & $74(64-84)(n=13231)$ \\
\hline $\begin{array}{l}\text { Median (IQR) systolic blood } \\
\text { pressure }\end{array}$ & $130(120-150)(n=2584)$ & $130(120-150)(n=2601)$ & $130(120-150)(n=5185)$ & $133(120-150)(n=13231)$ \\
\hline $\begin{array}{l}\text { Median (IQR) diastolic blood } \\
\text { pressure }\end{array}$ & $80(70-88)(n=2584)$ & $80(70-86)(n=2601)$ & $80(70-87)(n=5185)$ & $80(70-90)(n=13231)$ \\
\hline \multicolumn{5}{|l|}{ Risk indicators } \\
\hline Troponin positive $^{*}$ & $74.5(1860 / 2495)$ & $75.4(1900 / 2520)$ & $75.0(3760 / 5015)$ & $86.9(11329 / 13$ 042) \\
\hline ST depression ( $\geq 1 \mathrm{~mm})$ & $61.7(1602 / 2597)$ & $64.0(1673 / 2613)$ & $62.9(3275 / 5210)$ & $46.4(6211 / 13380)$ \\
\hline TIMI NSTE-ACS risk score $>2$ & $89.2(2259 / 2532)$ & $88.5(2261 / 2555)$ & $88.9(4520 / 5087)$ & $68.8(8954 / 13006)$ \\
\hline
\end{tabular}

IQR=interquartile range; TIMI NSTE-ACS=Thrombolysis In Myocardial Infarction non-ST elevation acute coronary syndrome.

*Positive result on testing for troponin I consisted of troponin I concentration $\geq 0.08 \mu \mathrm{g} / \mathrm{L}$ for first sample taken, as measured at central laboratory with use of Advia Centaur Tnl-Ultra Immunoassay (Siemens). 


\begin{tabular}{|c|c|c|c|c|}
\hline & & Planned non-invasive & & Planned invasive $(n=13$ \\
\hline & Ticagrelor $(n=2601)$ & Clopidogrel ( $n=2615)$ & Total $(n=5216)$ & 408) \\
\hline \multicolumn{5}{|c|}{ Type of acute coronary syndrome ${ }^{\star}$ at discharge } \\
\hline STEMI & $8.4(218 / 2594)$ & $8.9(233 / 2608)$ & $8.7(451 / 5202)$ & $49.1(6575 / 13380)$ \\
\hline NSTEMI & $55.6(1441 / 2594)$ & $56.3(1469 / 2608)$ & $55.9(2910 / 5202)$ & $37.7(5045 / 13380)$ \\
\hline Unstable angina pectoris or other & $36.0(935 / 2594)$ & $34.7(906 / 2608)$ & $35.4(1841 / 5202)$ & $13.2(1760 / 13380)$ \\
\hline \multicolumn{5}{|c|}{ Antithrombotic treatment during initial hospital admission } \\
\hline Aspirin & $95.2(2475 / 2600)$ & $94.7(2472 / 2611)$ & $94.9(4947 / 5211)$ & $98.0(13$ 128/13 390) \\
\hline Unfractionated heparin & $37.5(975)$ & $36.7(959)$ & $37.1(1934)$ & $66.0(8844)$ \\
\hline Low molecular weight heparin & $64.1(1668)$ & $63.6(1663)$ & $63.9(3331)$ & $47.1(6318)$ \\
\hline Fondaparinux & $5.0(131)$ & $4.8(125)$ & $4.9(256)$ & $1.9(253)$ \\
\hline Bivalirudin & $0.3(8)$ & $0.4(10)$ & $0.3(18)$ & $2.7(356)$ \\
\hline Glycoprotein Ilb/IIla inhibitor & $5.6(145)$ & $6.2(162)$ & $5.9(307)$ & $35.3(4730)$ \\
\hline \multicolumn{5}{|c|}{ Other drug from randomisation to end of study } \\
\hline$\beta$ blocker & $85.0(2212)$ & $83.9(2194)$ & $84.5(4406)$ & $85.7(11489)$ \\
\hline $\begin{array}{l}\text { ACE inhibitor/angiotensin receptor } \\
\text { blocker }\end{array}$ & $83.2(2162 / 2600)$ & $82.8(2162 / 2611)$ & $83.0(4324 / 5211)$ & $86.9(11637 / 13390)$ \\
\hline Cholesterol lowering drug (statin) & $89.9(2337)$ & $89.7(2345)$ & $89.8(4682)$ & $95.3(12778)$ \\
\hline Calcium antagonist & $29.5(767)$ & $30.1(786)$ & $29.8(1553)$ & $21.7(2905)$ \\
\hline Diuretic & $48.9(1272 / 2600)$ & $46.8(1222 / 2611)$ & $47.9(2494 / 5211)$ & $38.9(5213 / 13390)$ \\
\hline Proton pump inhibitor & $39.9(1038)$ & $39.0(1020)$ & $39.5(2058)$ & $54.0(7237)$ \\
\hline \multicolumn{5}{|l|}{ Invasive procedures } \\
\hline \multicolumn{5}{|l|}{ Coronary angiography: } \\
\hline Before discharge & $41.8(1088)$ & $41.9(1095)$ & $41.9(2183)$ & $96.9(12987)$ \\
\hline Any time during follow-up & $55.6(1447)$ & $55.4(1448)$ & $55.5(2895)$ & $97.6(13085)$ \\
\hline $\begin{array}{l}\text { Median (IQR) time to angiography } \\
\text { (hours) }\end{array}$ & $89(26-266)(n=1445)$ & $92(26-235)(n=1446)$ & $91(26-240)(\mathrm{n}=2891)$ & $0.6(0.1-3.8)(n=13083)$ \\
\hline \multicolumn{5}{|l|}{$\begin{array}{l}\text { Percutaneous coronary intervention } \\
\text { (PCI): }\end{array}$} \\
\hline Before discharge & $20.3(528)$ & $20.5(537)$ & $20.4(1065)$ & $76.8(10298)$ \\
\hline Any time during follow-up & $28.4(738)$ & $29.7(776)$ & $29.0(1514)$ & $78.0(10463)$ \\
\hline Median (IQR) time to PCI (hours) & $136(40-379)(n=738)$ & $144(42-391)(n=776)$ & $141(41-383)(n=1514)$ & $0.8(0.3-3.0)(n=10462)$ \\
\hline \multicolumn{5}{|l|}{$\begin{array}{l}\text { Coronary artery bypass grafting } \\
\text { (CABG): }\end{array}$} \\
\hline Before discharge & $4.2(108)$ & $3.8(100)$ & $4.0(208)$ & $5.7(762)$ \\
\hline Any time during follow-up & $11.0(287)$ & $10.4(272)$ & $10.7(559)$ & $10.0(1340)$ \\
\hline Median (IQR) time to CABG (hours) & $609(306-1682)(n=287)$ & $642(308-1852)(n=272)$ & $623(307-1742)(n=559)$ & $240(92-1145)(n=1340)$ \\
\hline \multicolumn{5}{|c|}{$\begin{array}{l}\text { ACE=angiotensin converting enzyme; IQR=interquartile range; NSTEMI=non-ST segment elevation myocardial infarction; STEMI=ST segment elevation myocardial } \\
\text { infarction. } \\
\text { *Defined by final diagnosis of index event. }\end{array}$} \\
\hline
\end{tabular}




\begin{tabular}{|c|c|c|c|c|}
\hline & Ticagrelor $(n=2601)$ & Clopidogrel $(n=2615)$ & Hazard ratio $(95 \% \mathrm{Cl})$ & P value* \\
\hline \multicolumn{5}{|l|}{ Primary objective } \\
\hline $\begin{array}{l}\text { Cardiovascular death + myocardial infarction (excluding silent) + } \\
\text { stroke }\end{array}$ & $12.0(295)$ & $14.3(346)$ & $0.85(0.73$ to 1.00$)$ & 0.045 \\
\hline \multicolumn{5}{|l|}{ Secondary objectives } \\
\hline Myocardial infarction & $7.2(176)$ & $7.8(187)$ & $0.94(0.77$ to 1.15$)$ & 0.555 \\
\hline Cardiovascular death & $5.5(132)$ & $7.2(173)$ & $0.76(0.61$ to 0.96$)$ & 0.019 \\
\hline All cause death & $6.1(147)$ & $8.2(195)$ & 0.75 (0.61 to 0.93$)$ & 0.010 \\
\hline Non-cardiovascular death & $0.6(15)$ & $1.0(22)$ & $0.68(0.35$ to 1.31$)$ & 0.252 \\
\hline Stroke: & $2.1(50)$ & $1.7(37)$ & $1.35(0.89$ to 2.07$)$ & 0.162 \\
\hline Ischaemic & $1.5(37)$ & $1.4(32)$ & & 0.530 \\
\hline Haemorrhagic & $0.5(11)$ & $0.2(4)$ & & 0.069 \\
\hline Unknown & $0.2(5)$ & $0.06(1)$ & & 0.124 \\
\hline $\begin{array}{l}\text { Cardiovascular death + myocardial infarction + stroke + composite } \\
\text { ischaemic events } \dagger+\text { other arterial thrombotic events }\end{array}$ & $18.6(460)$ & $20.3(492)$ & $0.94(0.82$ to 1.06$)$ & 0.309 \\
\hline \multicolumn{5}{|l|}{ Primary safety objective } \\
\hline Total major bleeding & $11.9(272)$ & $10.3(238)$ & $1.17(0.98$ to 1.39$)$ & 0.079 \\
\hline Life threatening or fatal bleeding & $5.5(125)$ & $5.6(129)$ & $0.99(0.77$ to 1.26$)$ & 0.911 \\
\hline Intracranial bleeding & $0.5(11)$ & $0.2(4)$ & $2.83(0.90$ to 8.90$)$ & 0.075 \\
\hline Other major bleeding & $6.8(154)$ & $4.9(114)$ & $1.38(1.09$ to 1.76$)$ & 0.009 \\
\hline \multicolumn{5}{|l|}{ Secondary safety objectives-components of major bleeding events } \\
\hline Non-CABG related & $4.0(90)$ & $3.1(71)$ & $1.30(0.95$ to 1.77$)$ & 0.103 \\
\hline CABG related & $8.3(189)$ & $7.5(174)$ & $1.11(0.90$ to 1.36$)$ & 0.335 \\
\hline Coronary procedure related & $9.2(211)$ & $8.2(191)$ & $1.13(0.93$ to 1.37$)$ & 0.231 \\
\hline Non-coronary procedure related & $0.04(1)$ & $0.4(7)$ & $0.15(0.02$ to 1.19$)$ & 0.072 \\
\hline \multicolumn{5}{|l|}{ Secondary safety objectives-major or minor bleeding events } \\
\hline Total & $16.4(378)$ & $14.4(332)$ & $1.17(1.01$ to 1.36$)$ & 0.0358 \\
\hline Non-CABG related & $8.3(190)$ & $6.7(151)$ & $1.29(1.04$ to 1.60$)$ & 0.0182 \\
\hline CABG related & $8.9(202)$ & $8.5(196)$ & $1.05(0.86$ to 1.28$)$ & 0.6341 \\
\hline Coronary procedure related & $10.8(250)$ & $10.0(235)$ & $1.09(0.91$ to 1.30$)$ & 0.3657 \\
\hline Non-coronary procedure related & $0.5(11)$ & $0.8(16)$ & $0.70(0.33$ to 1.51$)$ & 0.3632 \\
\hline \multicolumn{5}{|l|}{ Other safety objectives } \\
\hline \multicolumn{5}{|l|}{ TIMI defined cut-off point for major bleeding: } \\
\hline Total & $7.9(181)$ & $7.2(164)$ & $1.13(0.91$ to 1.39$)$ & 0.270 \\
\hline Non-CABG related & $2.8(61)$ & $2.2(47)$ & $1.33(0.91$ to 1.94$)$ & 0.142 \\
\hline CABG related & $5.4(124)$ & $5.3(122)$ & $1.03(0.80$ to 1.33$)$ & 0.799 \\
\hline \multicolumn{5}{|l|}{ Transfusion of blood products: } \\
\hline PRBCs or whole blood & $7.6(174)$ & $7.2(172)$ & $1.03(0.83$ to 1.27$)$ & 0.804 \\
\hline Platelets & $1.3(30)$ & $1.2(27)$ & $1.13(0.67$ to 1.90$)$ & 0.645 \\
\hline Fresh frozen plasma & $2.4(55)$ & $2.2(50)$ & $1.12(0.76$ to 1.64$)$ & 0.565 \\
\hline
\end{tabular}

$\mathrm{CABG}=$ coronary artery bypass grafting; $\mathrm{PRBC}=$ packed red blood cells; $\mathrm{TIMI}=$ Thrombolysis In Myocardial Infarction.

${ }^{*}$ From univariate Cox model.

†Severe recurrent cardiac ischaemia, recurrent cardiac ischaemia, and transitory ischaemic attack. 


\section{Figures}

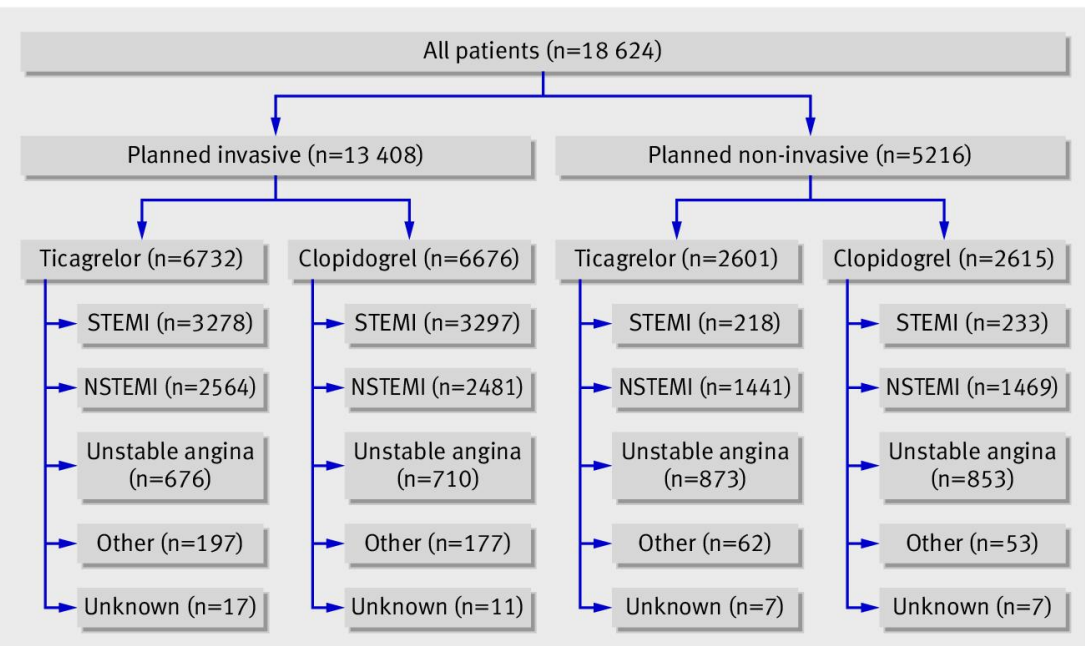

Fig 1 Flowchart showing number of patients intended for invasive and non-invasive management at time of randomisation, randomised to ticagrelor or clopidogrel, and final diagnosis at discharge. NSTEMI=non-ST segment myocardial infarction; STEMI=ST segment myocardial infarction

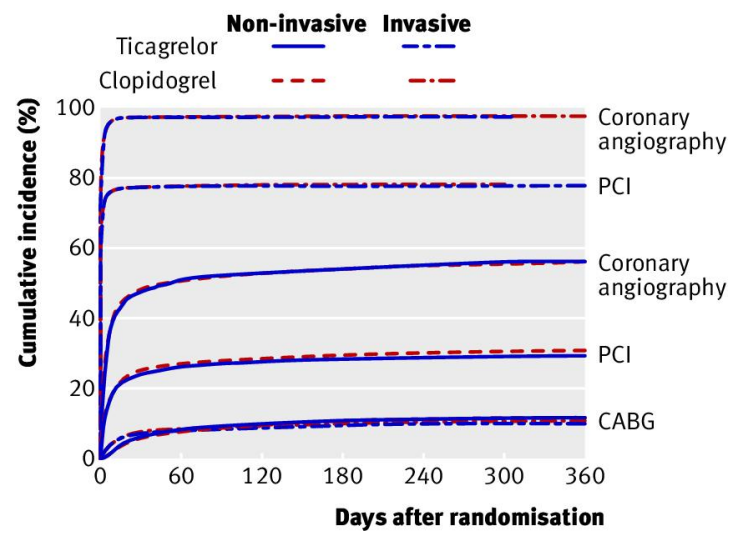

Fig 2 Cumulative incidence of cardiac catheterisation, percutaneous coronary intervention (PCl) and coronary artery bypass grafting $(\mathrm{CABG})$ in patients intended for non-invasive management and randomised to ticagrelor or clopidogrel 


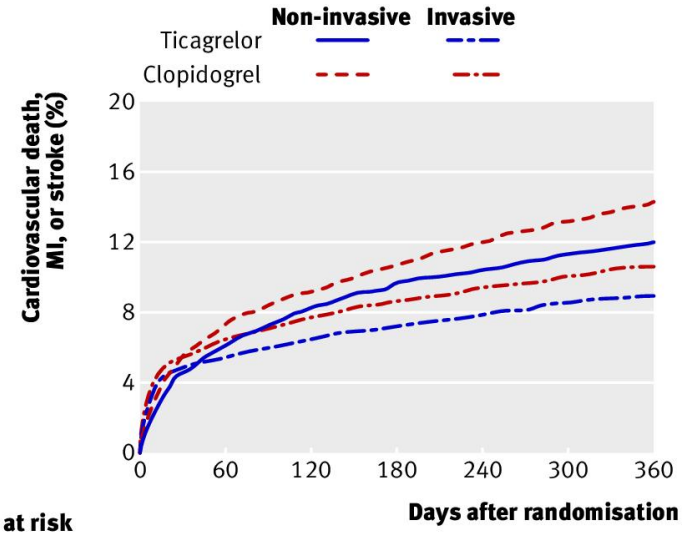

No at risk

Invasive

$\begin{array}{llllllll}\text { Ticagrelor } & 6732 & 6236 & 6134 & 5972 & 4889 & 3735 & 3048\end{array}$

Clopidogrel $\quad \begin{array}{lllllll}6676 & 6129 & 6034 & 5881 & 4815 & 3680 & 2965\end{array}$

\section{Non-invasive}

Ticagrelor $\begin{array}{llllllll}2601 & 2392 & 2326 & 2247 & 1854 & 1426 & 1099\end{array}$

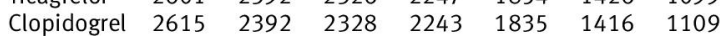

Fig 3 Cumulative incidence of primary composite of cardiovascular death, myocardial infarction (MI), and stroke in ticagrelor and clopidogrel groups in patients intended for invasive and non-invasive management at time of randomisation



No at risk

Days after randomisation

Invasive

$\begin{array}{llllllll}\text { Ticagrelor } & 6732 & 6439 & 6375 & 6241 & 5141 & 3951 & 3233\end{array}$

$\begin{array}{llllllll}\text { Clopidogrel } & 6676 & 6376 & 6331 & 6209 & 5114 & 3917 & 3164\end{array}$

Non-invasive

$\begin{array}{lllllllll}\text { Ticagrelor } & 2601 & 2485 & 2447 & 2385 & 1978 & 1531 & 1186\end{array}$

$\begin{array}{llllllll}\text { Clopidogrel } & 2615 & 2488 & 2448 & 2380 & 1965 & 1524 & 1200\end{array}$

Fig 4 Cumulative incidence of total mortality in ticagrelor and clopidogrel groups in patients intended for invasive and non-invasive management at time of randomisation 


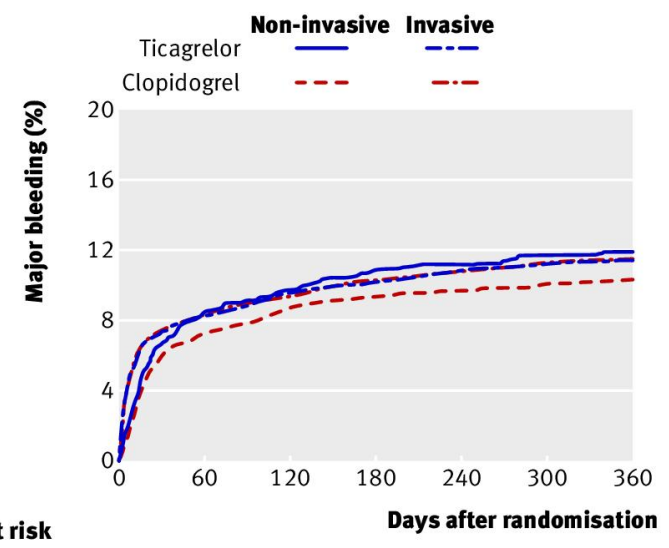

No at risk

Invasive

Ticagrelor $\quad \begin{array}{llllllll}6651 & 5238 & 4948 & 4766 & 3730 & 2748 & 2521\end{array}$

$\begin{array}{lllllllll}\text { Clopidogrel } & 6585 & 5220 & 4985 & 4798 & 3756 & 2760 & 2507\end{array}$

Non-invasive

$\begin{array}{llllllll}\text { Ticagrelor } & 2584 & 2008 & 1878 & 1779 & 1399 & 1035 & 912\end{array}$

$\begin{array}{llllllll}\text { Clopidogrel } & 2601 & 2085 & 1945 & 1872 & 1453 & 1081 & 972\end{array}$

Fig 5 Cumulative incidence of major bleeding in ticagrelor and clopidogrel groups in patients intended for invasive and non-invasive management at time of randomisation 